\title{
Decarbonising the EU Energy System by 2050: An important role for BECCS
}

\section{Introduction}

The European Union has established a target of reducing greenhouse gas (GHG) emissions by 80-95\% below 1990 levels by 2050 (European Commission, 2011a). Various studies have sought to examine how this may be achieved, using a range of modelling approaches and scenario designs (e.g. Capros et al, 2014; Capros et al, 2012; Edenhofer et al, 2010; European Commission, 2011a; Hubler \& Loschel, 2013; Knopf et al, 2013). This paper seeks to add to this literature, by using the recently-developed European TIMES Model (ETM-UCL) to

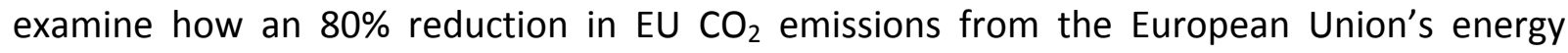
system by 2050 (from 1990 levels) may be achieved at least-cost. A description of the model is provided in Section 2, followed by a discussion in Section 3 of the scenarios and assumptions applied to the model. Section 4 presents headline results, including $\mathrm{CO}_{2}$ emissions and primary energy use, whilst Section 5 discusses sector-level developments. Section 6 discusses financial considerations, including the additional costs of decarbonisation and marginal $\mathrm{CO}_{2}$ abatement costs to 2050. Section 7 provides a discussion of the results, including a comparison with other modelling activities. Section 8 concludes.

\section{The European TIMES Model (ETM-UCL)}

The European TIMES Model (ETM-UCL) is a dynamic partial equilibrium energy system model with an inter-temporal objective function to minimise total discounted system costs, based on the TIMES model generator. It is a technology-rich, bottom-up model, which tracks energy flows and related costs from resource supply through conversion and distribution to end-use demands. The model acts like an EU central planner with perfect foresight to construct an energy system that minimises the total discounted cost, taking account of any scenario parameters and constraints, of meeting a prescribed level of energy service demands.

The model covers the twenty-eight Member States of the European Union (the 'EU28'), grouped into nine 'regions', as described in Table 1, along with a 'global' region. 


\begin{tabular}{|c|c|c|}
\hline Region Code & Region Name & Countries Within Region \\
\hline BNL & Benelux & Belgium, Netherlands and Luxembourg \\
\hline DEU & Germany & Germany \\
\hline FRA & France & France \\
\hline IAM & Italy, Austria, Malta & Italy, Austria and Malta \\
\hline IBE & Iberia & Spain and Portugal \\
\hline SDF & Sweden, Denmark, Finland & Sweden, Denmark and Finland \\
\hline UKI & United Kingdom and Ireland & UK and Ireland \\
\hline EEN & Eastern Europe - North & Estonia, Lithuania, Latvia, Czech Republic, Slovakia and Poland \\
\hline EES & Eastern Europe - South & $\begin{array}{c}\text { Slovenia, Hungary, Romania, Bulgaria, Greece, Cyprus and } \\
\text { Croatia }\end{array}$ \\
\hline
\end{tabular}

Each European region is modelled with supply, power generation and demand side sectors, and is linked through trade in energy products (including electricity). The 'global' region may be considered simply as a 'basket of resources' from which EU regions may import energy products (except electricity). The model is calibrated to its base year of 2010, with energy service demands projected into the future using the exogenously calculated drivers of GDP, population, household numbers and sectoral output (linked to GDP), for each region. There is no elasticity of demand in the model, so that the energy service demands in each scenario are the same. Cost estimates are therefore higher than would be expected in a reality that included demand response. A standard annual discount rate of $3.5 \%$ is applied to all future monetary values, which are measured in US\$2010. For more information on ETM-UCL, please refer to Solano \& Pye (2014).

\section{Scenario Design and Assumptions}

This paper analyses a 'Reference' and a 'Policy Success' Scenario, both of which are described below. However, both scenarios share a number of key characteristics ${ }^{1}$.

\subsection{Key Scenario Common Characteristics}

An assessment horizon of 2050 is used, with projections beginning in the base year of 2010. Results are reported for five-year time periods. The trajectory of the key drivers of GDP, population growth and number of households, which drive energy service demand in the economy, are the same in each scenario. These values are taken from the IEA's 'Energy Technology Perspectives 2012' for the European Union, and are presented in Table. These

\footnotetext{
${ }^{1}$ See Solano \& Drummond (2014) for a description and results of alternative Policy Success scenarios.
} 
trajectories are also common across the different mitigation ambition scenarios (2DS, 4DS and 6DS) presented by the IEA (2012) 2 .

Table 2 - Key Energy Service Demand Drivers (Source: IEA, 2012)

\begin{tabular}{|c|c|c|c|c|c|}
\hline Driver & 2015 & 2020 & 2030 & 2040 & 2050 \\
\hline Population & $506 \mathrm{~m}$ & $511 \mathrm{~m}$ & $516 \mathrm{~m}$ & $515 \mathrm{~m}$ & $512 m$ \\
\hline Households & $217 \mathrm{~m}$ & - & $238 \mathrm{~m}$ & - & $252 m$ \\
\hline Annual GDP Growth ${ }^{3}$ & \multicolumn{2}{|c|}{$2 \%(2009-20)$} & $1.8 \%(2020-30)$ & \multicolumn{2}{|c|}{$1.7 \%(2030-50)$} \\
\hline
\end{tabular}

Each scenario also assumes that the GHG emissions (taken as synonymous with $\mathrm{CO}_{2}$ for the purposes of this analysis) and renewable energy targets of the EU's 2020 Climate and Energy Package are achieved - two of the '20-20-20' targets. For practical reasons, the energy efficiency target is not imposed.

In order to reflect the key mechanisms employed to deliver the $\mathrm{CO}_{2}$ target, for the power and heat generation and 'industry' sectors ${ }^{4}$, EU-wide $\mathrm{CO}_{2}$ limits are set in 2015 and 2020 equal to the EU ETS cap for these years ${ }^{5}$. $\mathrm{CO}_{2}$ emissions for all non-ETS sectors ${ }^{6}$ subject to the Effort Sharing Decision (ESD), are capped in 2015 and 2020 at the mandated level (controlled for the removal of non- $\mathrm{CO}_{2} \mathrm{GHGs}$ ), for each region (aggregated from Member State caps) ${ }^{7}$.

The Renewable Energy Directive (RED) imposes upon each Member State a binding target to ensure a certain proportion of their gross final energy consumption is obtained from renewables by 2020. Table presents these targets by Member State, aggregated according to the model's regions. A sub-target requires that $10 \%$ of final energy consumption in transport is renewable by 2020, and is equally applicable across all Member States. In the model this target is mapped to require at least $10 \%$ of liquid transport fuels to be biofuel, (by which the vast majority of this target is likely to be achieved), in each EU28 region.

\footnotetext{
${ }^{2}$ Actual values used in the model are calculated by Cambridge Econometrics for the E3ME model, and vary by region. However, these values aggregate to match those presented in Table 2.

${ }^{3}$ Actual values for GDP and sectoral output used in the model are calculated by Cambridge Econometrics for the E3ME model, and vary by region, but GDP match the values presented in the table for the EU as a whole.

4 'Industry' is disaggregated in the model to Chemicals, Iron \& Steel, Non-Ferrous Metals, Pulp \& Paper and 'Other' Industry.

${ }^{5}$ Based on a $1.74 \%$ Linear Reduction factor, and scaled down to account for the removal of Norway and Iceland from the study. Permit 'banking' and 'borrowing' provisions are not considered.

${ }^{6}$ Excluding Land Use, Land Use Change and Forestry (LULUCF), Indirect Land Use Change (ILUC), international aviation and shipping emissions.

7 The ESD establishes binding annual GHG emission caps for each Member State between 2013 and 2020 covering all non-EU ETS sectors. For more information on the ESD and the cap levels set, see: http://ec.europa.eu/clima/policies/effort/index_en.htm
} 
Table 3 - Renewable Energy Directive Targets

\begin{tabular}{|c|c|c|c|}
\hline Region & Member State & Member State Target & ETM-UCL Regional Target \\
\hline \multirow{3}{*}{ BNL } & Belgium & $13 \%$ & \multirow{3}{*}{$13 \%$} \\
\hline & Netherlands & $14 \%$ & \\
\hline & Luxembourg & $11 \%$ & \\
\hline DEU & Germany & $18 \%$ & $18 \%$ \\
\hline \multirow{6}{*}{ EEN } & Estonia & $25 \%$ & \multirow{6}{*}{$22 \%$} \\
\hline & Lithuania & $23 \%$ & \\
\hline & Latvia & $40 \%$ & \\
\hline & Czech Republic & $13 \%$ & \\
\hline & Slovak Republic & $14 \%$ & \\
\hline & Poland & $15 \%$ & \\
\hline \multirow{7}{*}{ EES } & Slovenia & $25 \%$ & \multirow{7}{*}{$18 \%$} \\
\hline & Hungary & $13 \%$ & \\
\hline & Romania & $24 \%$ & \\
\hline & Bulgaria & $16 \%$ & \\
\hline & Greece & $18 \%$ & \\
\hline & Cyprus & $13 \%$ & \\
\hline & Croatia & $20 \%$ & \\
\hline FRA & France & $23 \%$ & $23 \%$ \\
\hline \multirow{3}{*}{ IAM } & Italy & $17 \%$ & \multirow{3}{*}{$20 \%$} \\
\hline & Austria & $34 \%$ & \\
\hline & Malta & $10 \%$ & \\
\hline \multirow{2}{*}{ IBE } & Spain & $20 \%$ & \multirow{2}{*}{$26 \%$} \\
\hline & Portugal & $31 \%$ & \\
\hline \multirow{3}{*}{ SDF } & Sweden & $49 \%$ & \multirow{3}{*}{$39 \%$} \\
\hline & Denmark & $30 \%$ & \\
\hline & Finland & $38 \%$ & \\
\hline \multirow{2}{*}{ UKI } & United Kingdom & $15 \%$ & \multirow{2}{*}{$16 \%$} \\
\hline & Ireland & $16 \%$ & \\
\hline
\end{tabular}

Common assumptions are also applied regarding nuclear capacity. Constraints are applied that reduce existing capacity in different EU regions in line with expected shutdown dates according to the World Nuclear Association (2013), as of October 2013. This includes the phase-out of all German nuclear capacity by 2022 (Bruninx et al, 2013). Constraints are also applied to the introduction of new nuclear capacity in different regions, to reflect differences in public opinion and expected government strategies. Again, such judgements are based on World Nuclear Association assessments of the existing landscape across these regions. The constraints applied are presented in Table . In summary, total EU nuclear capacity is limited to 2010 levels at any time over the assessment horizon. 
Table 4 - Constraints on New Nuclear Construction

\begin{tabular}{|c|c|}
\hline Region Code & New Nuclear \\
\hline DEU & \multirow{2}{*}{ No new build permitted } \\
\hline IAM & \\
\hline $\mathrm{BNL}$ & \multirow{5}{*}{$\begin{array}{c}\text { Permitted to reach total } 2010 \text { capacity (i.e. } \\
\text { permitted to replace closing domestic } \\
\text { installations) }\end{array}$} \\
\hline FRA & \\
\hline IBE & \\
\hline SDF & \\
\hline UKI & \\
\hline EEN & \multirow{2}{*}{$\begin{array}{l}\text { New build permitted, but capped to total EL } \\
\text { capacity in } 2010 \text { (e.g. permitted to replace } \\
\text { reduced capacity seen in other regions) }\end{array}$} \\
\hline EES & \\
\hline
\end{tabular}

No further sector-specific instruments, such as $\mathrm{CO}_{2}$ emission and energy efficiency regulations for new cars and buildings, are considered.

\subsection{Reference Scenario}

In this scenario, post-2020 efforts to curb emissions are abandoned at both a global and EUlevel, producing a 'business as usual' least-cost energy system, with an emissions pathway expected to lead to an average global surface temperature increase of around $6^{\circ} \mathrm{C}$ by 2100 .

As GHG mitigation is no longer an ambition (at global or EU-level) in this scenario, demand for fossil fuels is likely to increase substantially from current levels, leading to higher prices than in a scenario in which demand for these resources is constrained. Table presents projected import prices for key fossil fuels used by the IEA (2012) in their $6^{\circ} \mathrm{C}(6 \mathrm{DS}), 4^{\circ} \mathrm{C}$ (4DS) and $2^{\circ} \mathrm{C}(2 \mathrm{DS})$ scenarios. For the Reference scenario, the 6DS prices are imposed..$^{8}$

Table 5 - IEA Fossil Fuel Price Projections (Source: IEA, 2012)

\begin{tabular}{|c|c|c|c|c|c|c|c|c|c|}
\hline Fossil Fuel & $\begin{array}{c}\text { IEA } \\
\text { Scenario }\end{array}$ & 2010 & 2020 & 2025 & 2030 & 2035 & 2040 & 2045 & 2050 \\
\hline \multirow{2}{*}{$\begin{array}{c}\text { Crude Oil (2010 } \\
\text { US\$/bbl) }\end{array}$} & 2DS & 78 & 97 & 97 & 97 & 97 & 92 & 89 & 87 \\
\hline & 6DS & 78 & 118 & 127 & 134 & 140 & 143 & 146 & 149 \\
\hline \multirow{2}{*}{$\begin{array}{c}\text { Steam Coal } \\
\qquad(2010 \\
\text { US\$/tonne) }\end{array}$} & 2DS & 99 & 93 & 83 & 74 & 68 & 64 & 62 & 60 \\
\hline & 6DS & 99 & 109 & 113 & 116 & 118 & 121 & 126 & 126 \\
\hline \multirow{2}{*}{$\begin{array}{c}\text { Gas (Europe) } \\
(2010\end{array}$} & 2DS & 7 & 10 & 10 & 10 & 9 & 9 & 8 & 8 \\
\hline & 6DS & 7 & 11 & 12 & 13 & 13 & 13 & 14 & 14 \\
\hline
\end{tabular}

\footnotetext{
8 In the Reference scenario, import prices for different biomass products are $\$ 5-10 / \mathrm{PJ}$ in 2010 , remaining static over time. In the Policy Success scenario, these prices approximately double by 2050 , reflecting their greatly increased use.
} 


\subsection{Policy Success Scenario}

The 'Policy Success' (PS) scenario assumes that global and EU-level ambition is increased, with the EU achieving at least an $80 \%$ reduction in $\mathrm{CO}_{2}$ emissions from 1990 levels. In the model, an absolute cap equivalent to this reduction is applied to $\mathrm{CO}_{2}$ emissions from the EU's energy system for 2050. Whilst no other explicit targets are implemented between 2020 and 2050 (other than the nuclear constraints already described), in order to produce informative results some 'realism' constraints are applied to prevent the unrealistic concentration of investment in and utilisation of mitigation technologies in the last few years of the assessment horizon, as a result of assumed technology cost reductions in the model and discounting of future costs: annual $\mathrm{CO}_{2}$ emissions (post-2020) are not permitted to exceed 2020 levels; renewable energy consumption may not reduce below 2020 levels; and $\mathrm{CO}_{2}$ mitigation may not exceed a 3.5\% annual reduction between 2010 and 2040, and 8\% between 2040 and $2050^{9}$.

It is also assumed that the 2050 emission and renewables targets set unilaterally by the UK and Germany will be achieved. The UK must reduce GHG emissions by $80 \%$ in 2050 (from 1990 levels), as enshrined in the Climate Change Act 2008. This is implemented in the model by requiring a minimum $80 \%$ reduction in $\mathrm{CO}_{2}$ in the UK \& Ireland region. Germany's 'Energy Transition' also envisages a minimum 80\% reduction in GHGs between 1990 and 2050, alongside an $80 \%$ renewable electricity target to be achieved as part of a wider ambition of $60 \%$ renewables across all energy consumption by 2050 (Buchan, 2012). All three targets are implemented in this scenario (with the GHG target translated to $\mathrm{CO}_{2}$ only). To reflect the lower fossil fuel demand in this scenario, the 2DS fossil fuel prices listed in Table are used.

\section{Summary of Scenario Results - Overall}

\section{$4.1 \mathrm{CO}_{2}$ Emissions}

\footnotetext{
9 The 3.5\% value generally represents the upper end of possible annual reduction rates produced by the literature (den Elzen et al (2010)), whilst the increase to $8 \%$ maintains the ability for the model to produce a solution.
} 
Figure 1 and Figure 2 present the $\mathrm{CO}_{2}$ emissions profile for the Reference and Policy Success scenarios.

Figure $1-\mathrm{CO}_{2}$ Emissions by Sector - Reference

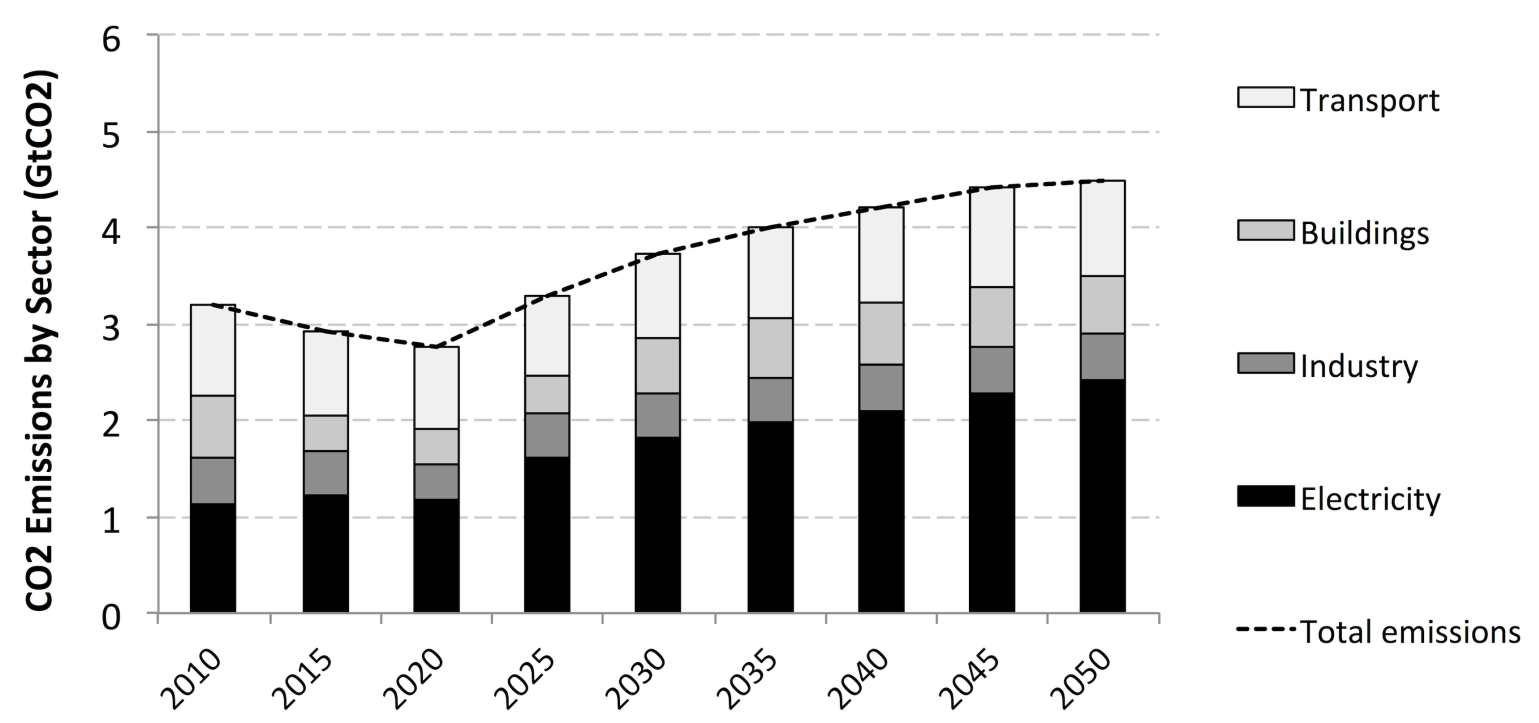

Figure $2-\mathrm{CO}_{2}$ Emissions by Sector - Policy Success

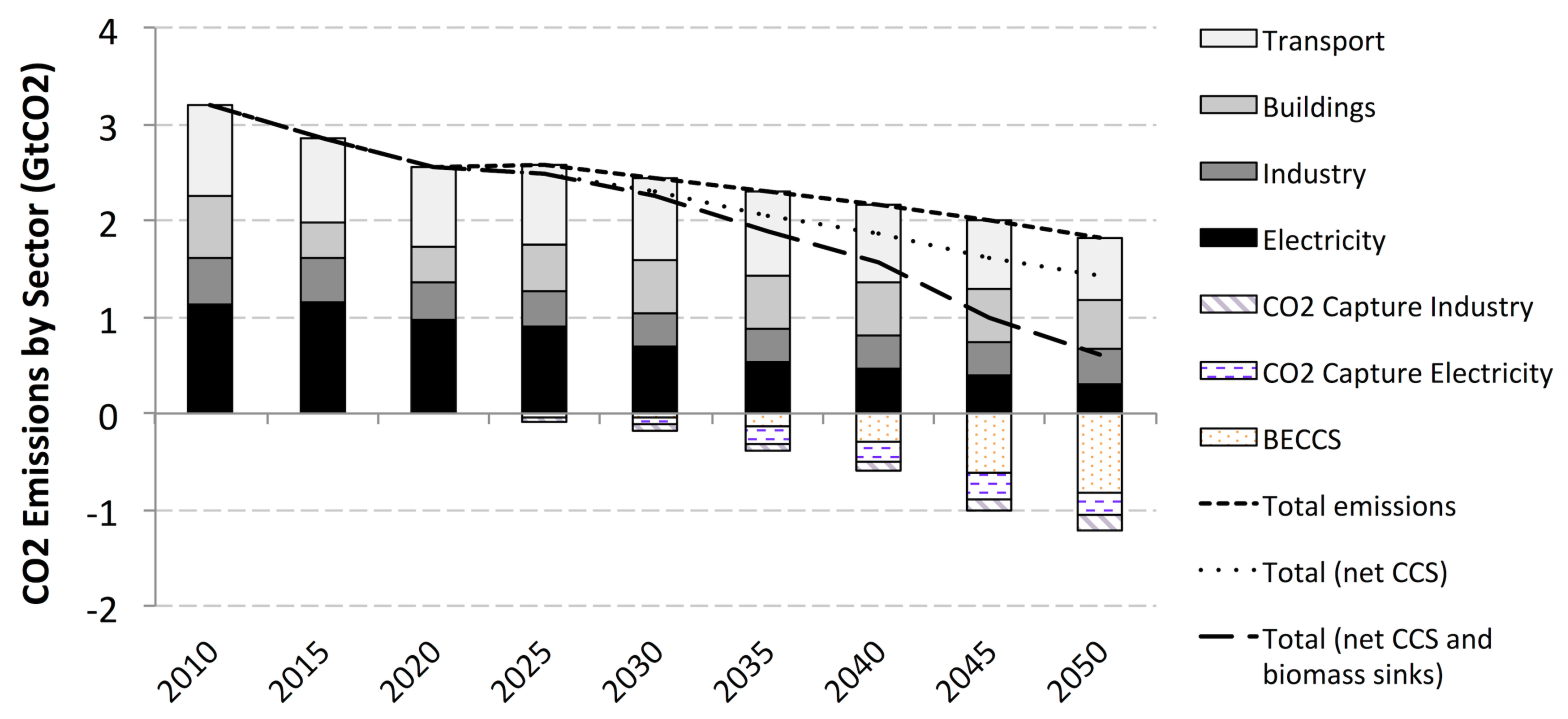

By construction, emission trends between 2010 and 2020 are very similar (both overall and in sectoral contribution), with $2020 \mathrm{CO}_{2}$ emissions 15-20\% lower than 2010 levels, and 20-25\% lower than 1990 levels (significantly exceeding the EU 20\% target). On the other hand, $\mathrm{CO}_{2}$ emission profiles between 2020 and 2050 are very different. With no post-2020 constraints, emissions in the Reference scenario rapidly increase to around 40\% above 2010 levels by 2050 (28\% above 1990), driven largely by rapid increases in power sector emissions. Conversely, Policy Success emissions reduce to 77\% below 2010 levels (81\% below 1990 levels), again substantially driven by changes in power sector emissions, and in particular, the introduction of carbon capture and sequestration (CCS) from 2025 onwards (becoming highly 
significant by 2050). BECCS is of particular importance, with net-negative power sector emissions achieved by 2040 (See Table ). By 2050, the levels of biomass sequestration exceed total $\mathrm{CO}_{2}$ emissions from the entire energy system.

The buildings sector contributes significantly to the achievement of the 2020 emissions targets in both scenarios. Whilst emissions increase after 2020, they remain below 2010 levels in in both scenarios (at $7 \%$ and $20 \%$ by 2050 , respectively). Transport and industrial emissions alter little between 2010 and 2020, and remain relatively stable to 2050 in the Reference. However, in Policy Success, 2050 transport emissions reduce by around a third between 2020 and 2050, whilst industrial emissions halve (driven substantially by the use of CCS on industrial processes).

Table 6 presents the proportional changes to $\mathrm{CO}_{2}$ emissions by 2050 from 1990 by region and EU-wide. Whilst regional change in the Reference is extremely varied, the range of developments in Policy Success is much smaller, with all regions experiencing significant reductions. Germany and the UK \& Ireland regions both achieve $80 \%$ reductions, although Germany remains the largest single emitter in both scenarios.

Table $6-\mathrm{CO}_{2}$ Reduction in 2050 from 1990 - EU and Regional

\begin{tabular}{|c|c|c|}
\hline Region & $\begin{array}{c}\text { \% Change in } 2050 \mathrm{CO}_{2} \text { emissions } \\
\text { from } \mathbf{1 9 9 0} \text { levels - Reference }\end{array}$ & $\begin{array}{c}\% \text { Change in } 2050 \mathrm{CO}_{2} \\
\text { emissions from } 1990 \\
\text { levels - Policy Success }\end{array}$ \\
\hline BNL & $34 \%$ & $-70 \%$ \\
\hline DEU & $28 \%$ & $-80 \%$ \\
\hline EEN & $5 \%$ & $-79 \%$ \\
\hline EES & $30 \%$ & $-85 \%$ \\
\hline FRA & $89 \%$ & $-86 \%$ \\
\hline IAM & $4 \%$ & $-74 \%$ \\
\hline IBE & $21 \%$ & $-85 \%$ \\
\hline SDF & $96 \%$ & $-87 \%$ \\
\hline UKI & $9 \%$ & $-80 \%$ \\
\hline EU-Wide & $28 \%$ & $-81 \%$ \\
\hline
\end{tabular}

\subsection{Primary Energy Use}

Figure 3 presents developments in primary energy use across the EU for the two scenarios. 
Figure 3 - EU Primary Energy Use

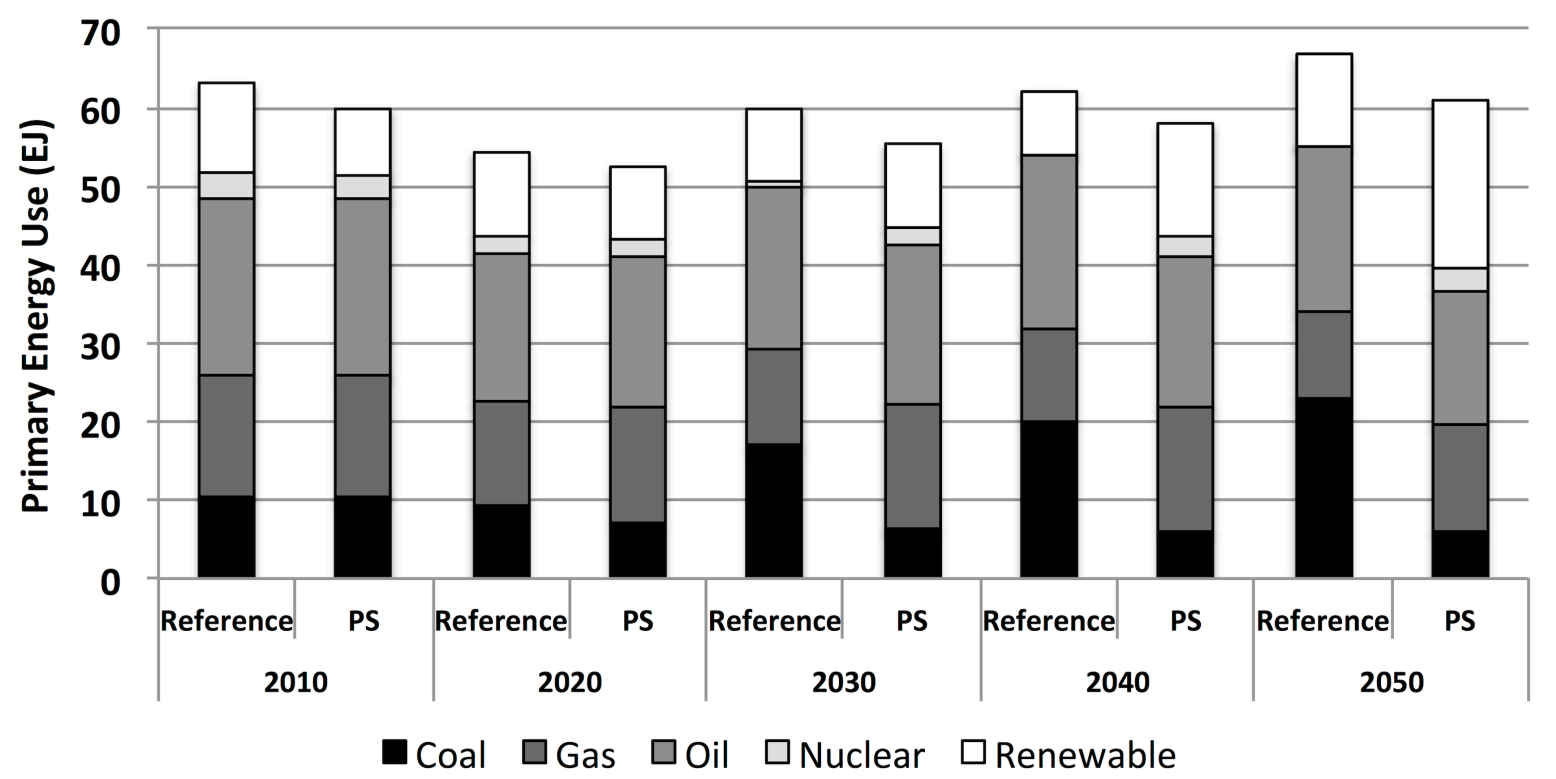

Trends in primary energy use are similar between 2010 and 2020 for the two scenarios, with a general decrease of around $9 \%$ over this time. This represents a $29 \%$ reduction against the projected baseline calculated under the Energy Efficiency Directive, thus the 2020 EU energy efficiency target of $20 \%$ is exceeded despite no explicit model constraint. The 2020 renewables target of $20 \%$ of final energy consumption is met by assumption in both scenarios. Total primary energy use in both scenarios subsequently rises again to approximately 2010 levels post-2020, driven by rapidly rising coal demand in the Reference (more than doubling by 2050 from 2010 levels), and renewables in Policy Success (particularly wind, solar and biomass ${ }^{10}$ ). Supply of nuclear is eliminated by 2045 in the Reference, whilst remaining largely constant in Policy Success over time.

It is interesting to see whether the Policy Success scenario, which is cost-optimal for the 2050 carbon reduction target, achieves the EU's 2030 energy and climate targets (40\% reduction in GHGs (from 1990 levels) and 27\% share of renewable energy in final energy consumption). Policy Success achieves $41 \%$ ( $\mathrm{CO}_{2}$ only) emission reduction, and $21 \%$ renewable energy by 2030. The EU's renewables target is therefore not on the cost-effective carbon emission trajectory, according to this model run at least, which instead chooses more rapid increases

\footnotetext{
${ }^{10}$ Imports of biomass to the EU increases from around 0.5EJ to 3EJ between 2010 and 2050, despite increasing import prices. In the Reference Scenario, biomass imports reduce to zero after 2020. Biomass potentials in the EU are set by region based on a review of the literature, and particularly the AEBIOM 2012 Annual Statistical Report on the Contribution of Biomass to the Energy System in the EU27.
} 
in investment in renewables towards the end of the assessment horizon (discussed in the Section 5).

\section{Summary of Scenario Results - Sectoral}

\subsection{Power Sector}

Figure 4 illustrates the development of the EU's electricity generation profile for the two scenarios.

Figure 4 - EU Electricity Generation Profiles

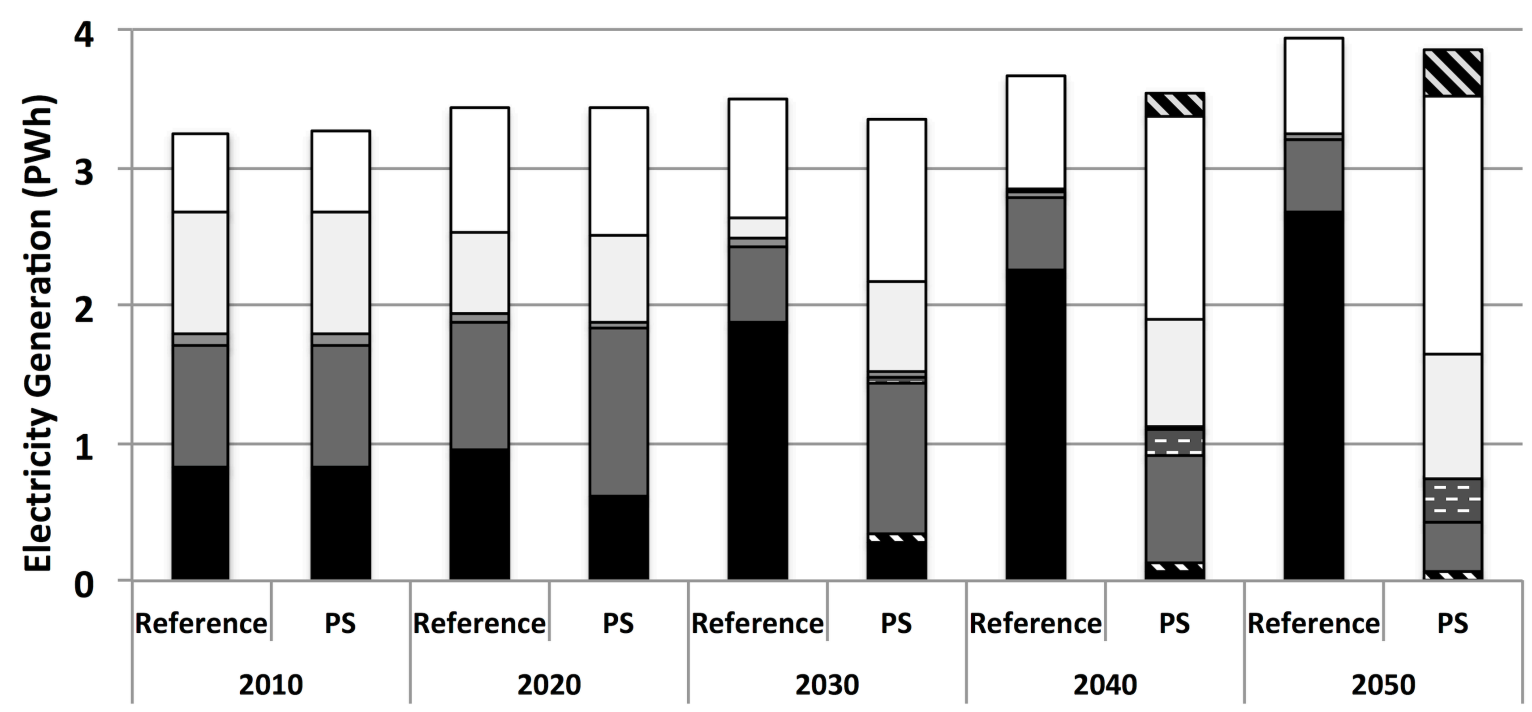

- Coal $\mathbf{\nabla}$ Coal CCS $\square$ Gas $\square$ Gas CCS $\square$ Oil $\square$ Nuclear $\square$ Renewable $\mathbf{\Delta}$ Biomass CCS

Total generation increases across both scenarios at a relatively equal pace. Renewable electricity accounts for around a quarter of generation (mostly hydro and wind) in both scenarios by 2020. After 2020, four key differences emerge. The first, and most significant, concerns coal generation. Whilst the Reference rapidly turns to coal (68\% by 2050 , accounting for the majority of the growth in coal in primary energy demand seen in Figure 3), it experiences a relatively steady decline in Policy Success (both abated and unabated), to become insignificant by 2050 . The second is investment in new nuclear capacity, which maintains 2010 generation levels over time in Policy Success (but reduces from around 27\% to $24 \%$ as a proportion of increasing total generation). Nuclear generation has ceased in the Reference by 2045 . The third difference is the increasing prevalence of renewables, which by 2050 accounts for $48 \%$ of generation by 2050 in Policy Success (excluding biomass with 
carbon capture and storage (BECCS), discussed below), with hydropower, wind (both onshore and offshore) and solar PV each accounting for approximately a third of this (with the latter exhibiting rapid growth from 2035). In the Reference, renewables account for $17 \%$ of generation by 2050 (mostly hydropower). The fourth and final key difference is the use of CCS in Policy Success (it is wholly absent in the Reference) - particularly in combination with biomass, producing negative total net emissions after 2040, as illustrated in Table ${ }^{11}$.

Table $7-\mathrm{CO}_{2}$ Intensity of EU Power Generation

\begin{tabular}{|c|c|c|c|c|c|c|c|c|c|}
\hline $\mathbf{g C O}_{2} / \mathbf{K W h}$ & 2010 & 2015 & 2020 & 2025 & 2030 & 2035 & 2040 & 2045 & 2050 \\
\hline Reference & 343 & 340 & 333 & 448 & 518 & 556 & 577 & 603 & 612 \\
\hline Policy Success & 343 & 324 & 282 & 260 & 177 & 82 & 30 & -25 & -49 \\
\hline
\end{tabular}

\subsection{Transport Sector}

Table 8 presents fuel consumption in road transport in the two scenarios, for 2010 and 2050.

Table 8 - Fuel Consumption by All Road Transport

\begin{tabular}{|c|c|c|c|c|}
\hline \multirow{2}{*}{ Energy Carrier } & & 2010 & \multicolumn{3}{|c|}{2050} \\
\hline \multirow{2}{*}{ Gasoline } & EJ & 3.8 & 2.6 & 2.5 \\
\cline { 2 - 5 } & $\%$ & $30 \%$ & $18 \%$ & $19 \%$ \\
\hline \multirow{2}{*}{ Diesel } & EJ & 8.5 & 10.2 & 6.1 \\
\cline { 2 - 5 } & $\%$ & $66 \%$ & $72 \%$ & $46 \%$ \\
\hline \multirow{2}{*}{ Natural Gas } & EJ & 0 & 0.5 & 0 \\
\hline \multirow{2}{*}{ LPG } & $\%$ & $0 \%$ & $3 \%$ & $0 \%$ \\
\hline \multirow{2}{*}{ Ethanol/Methanol } & EJ & 0.2 & 0.2 & 0 \\
\cline { 2 - 5 } & $\%$ & $2 \%$ & $2 \%$ & $0 \%$ \\
\hline \multirow{2}{*}{ Electricity } & $\%$ & $1 \%$ & $3 \%$ & 1.8 \\
\hline \multirow{2}{*}{ Hydrogen } & EJ & 0 & 0.3 & 0.5 \\
\hline \multirow{2}{*}{ Total } & $\%$ & $0 \%$ & $2 \%$ & $4 \%$ \\
\hline & EJ & 0 & 0 & 2.2 \\
\hline & $\%$ & $0 \%$ & $0 \%$ & $17 \%$ \\
\hline & EJ & 12.7 & 14.2 & 13.2 \\
\hline
\end{tabular}

In both scenarios road transport demand (in terms of vehicle-kms) grows by $70 \%$ between 2010 and 2050, but is satisfied by much more fuel-efficient vehicles, so that fuel demand grows by much less. As the model does not optimise modal split, the proportional

\footnotetext{
${ }^{11}$ Investment costs for different fossil fuel CCS technologies are initially set at $\$ 1,250-\$ 2,300 / G W$, with fixed operating costs (FOC) set at $\$ 50-92 / \mathrm{GW}$, and variable operating costs (VOC) set at $\$ 0.3-1.6 / \mathrm{GW}$. Investment costs for different BECCS technologies are set at $\$ 1,700-2,500 / \mathrm{GW}$, with FOC of $\$ 60-77 / \mathrm{GW}$, and VOC of $\$ 2$ 3/GW.
} 
contribution remains equal, with car travel meeting $70 \%$ of demand, Heavy Goods Vehicles (HVGs) 13\%, and Light Goods Vehicles (LGVs, which includes vans and medium-sized commercial trucks) $17 \%$. Related emissions increase by $5 \%$ in the Reference, and reduce by $32 \%$ in Policy Success - trends that are driven almost entirely by changes in the fuel mix as shown in Table 8.

Table $9-\mathrm{CO}_{2}$ intensity of road vehicles

\begin{tabular}{|c|c|c|c|}
\hline \multirow{2}{*}{ Vehicle } & $2010\left(\mathrm{gCO}_{2} / \mathrm{km}\right)$ & \multicolumn{2}{|c|}{$2050\left(\mathrm{gCO}_{2} / \mathrm{km}\right)$} \\
\cline { 3 - 4 } & 190 & Reference & Policy Success \\
\hline Cars & 550 & 135 & 95 \\
\hline HGVs & 750 & 620 & 245 \\
\hline HGV & & & 215 \\
\hline
\end{tabular}

Table 9 illustrates that the $\mathrm{CO}_{2}$ intensity of cars experiences the least change in both scenarios. This is driven by a broad switch to more efficient vehicles, that are cost-optimal even in the Reference case, though more so in Policy Success. In Policy Success, biofuels (ethanol/methanol) are also prominent in cars by 2050, accounting for over half of the growth of biofuels between 2010 and 2050 (with the remainder consumed in HGVs, discussed below). However, conventional cars, made competitive by the relatively low oil price, continue to satisfy 54\% of car transport demand by 2050 in Policy Success.

LGVs also experience relatively significant $\mathrm{CO}_{2}$ intensity reductions across both scenarios, delivered through a similar fuel mix transition as cars (although with a rapid increase in plugin hybrid electric vehicles (PHEVs) post-2020). Conventional vehicles retain a $40 \%$ share of LGV travel demand in the Reference by 2050 , and $50 \%$ in Policy Success (again, likely due to reduced oil import prices, with the remainder a combination of electric hybrid, biofuel, LPG and natural gas vehicles). Both scenarios produce a rapid increase in biofuels for HGVs between 2010 and 2020, in order to satisfy the 2020 renewables requirement for transport fuels. Whilst in the Reference biofuels are phased out post-2020 in favour of a return to diesel, they remain in the HGV fuel mix at roughly the same proportion to 2050 in Policy Success. Hydrogen is also introduced in Policy Success from 2030, becoming significant by 2050, and satisfying around half of HGV energy demand and accounting for the entirety of hydrogen use in the energy system.

\subsection{Buildings Sector}


Table 10 presents the final energy consumption profile in the buildings (residential and commercial) sector, for 2010 and 2050.

Table 10 - Buildings Final Energy Consumption

\begin{tabular}{|c|c|c|c|c|}
\hline \multicolumn{2}{|c|}{ Energy Carrier } & 2010 & \multicolumn{3}{|c|}{2050} \\
\hline \multirow{2}{*}{ Coal } & EJ & 0.5 & 0.4 & 0.4 \\
\cline { 2 - 5 } & $\%$ & $3 \%$ & $2 \%$ & $2 \%$ \\
\hline \multirow{2}{*}{ Natural Gas } & EJ & 7 & 7.6 & 7.5 \\
\cline { 2 - 5 } & $\%$ & $36 \%$ & $37 \%$ & $40 \%$ \\
\hline \multirow{2}{*}{ Electricity } & EJ & 6.1 & 8 & 7.7 \\
\cline { 2 - 5 } & $\%$ & $31 \%$ & $39 \%$ & $40 \%$ \\
\hline \multirow{2}{*}{ Oil Products } & EJ & 2.6 & 1.5 & 1.3 \\
\cline { 2 - 5 } & $\%$ & $14 \%$ & $7 \%$ & $7 \%$ \\
\hline \multirow{2}{*}{ District Heat } & EJ & 1.4 & 1 & 1.4 \\
\cline { 2 - 5 } & $\%$ & $7 \%$ & $5 \%$ & $7 \%$ \\
\hline \multirow{2}{*}{ Renewables } & EJ & 1.8 & 2.1 & 0.7 \\
\cline { 2 - 5 } & $\%$ & $9 \%$ & $10 \%$ & $4 \%$ \\
\hline Total & EJ & 19.3 & 20.6 & 19 \\
\hline
\end{tabular}

The total energy consumption and fuel profile of the buildings sector remains relatively stable over time and between scenarios, with the only notable development being the relatively modest shift to electricity at the expense of oil products, primarily in residential space heating (responsible for around $40 \%$ of building sector final energy demand across the assessment horizon). This relatively stable energy consumption profile explains the lack of significant changes in long-term emissions in this sector, in both scenarios.

However, these results must be considered in context of a projected increase in residential and commercial floor space between 2010 and 2050 (26\% and 38\%, respectively) (IEA, 2012). As a consequence, energy service demand for space heating in the residential alone increases by around $15 \%$ for both scenarios between 2010 and 2050, with household energy intensity decreasing by around $15 \%$ and $25 \%$ in the Reference and Policy Success scenarios, respectively. In the commercial sector, energy intensity decreases by $20 \%$ and $24 \%$ in the Reference and Policy Success scenarios, respectively. As the ETM-UCL does not consider building envelope efficiency measures (or demand response), and given that energy consumption profiles remain relatively static, such improvements are driven by the availability and deployment of end-use products of increasing efficiency (boilers, air conditioning units, white goods, etc.).

The lack of building envelope efficiency measures in the model means that the modelled costs of decarbonisation in Policy Success (discussed in Section 6) are likely to be towards the 
upper end of what might otherwise be expected, given that building energy efficiency is often regarded as having substantial and relatively cheap (including negative cost) energy-saving potential (Wesselink, Harmsen \& Eichhammer, 2010).

\subsection{Industry Sector}

Table 11 presents final energy consumption in the industrial sector, for 2010 and 2050

Table 11 - Industrial Final Energy Consumption

\begin{tabular}{|c|c|c|c|c|}
\hline \multirow{2}{*}{ Energy Carrier } & 2010 & \multicolumn{3}{|c|}{2050} \\
\hline \multirow{2}{*}{ Coal } & EJ & 1 & 2.8 & 0.4 \\
\cline { 2 - 5 } & $\%$ & $8 \%$ & $19 \%$ & $3 \%$ \\
\hline \multirow{2}{*}{ Natural Gas } & EJ & 4.2 & 2.1 & 2.5 \\
\cline { 2 - 5 } & $\%$ & $31 \%$ & $14 \%$ & $20 \%$ \\
\hline \multirow{2}{*}{ Electricity } & EJ & 3.7 & 3.8 & 3.7 \\
\cline { 2 - 5 } & $\%$ & $28 \%$ & $26 \%$ & $30 \%$ \\
\hline \multirow{2}{*}{ Oil Products } & EJ & 2.9 & 3.5 & 3.4 \\
\cline { 2 - 5 } & $\%$ & $21 \%$ & $23 \%$ & $27 \%$ \\
\hline \multirow{2}{*}{ Heat } & EJ & 0.6 & 0.4 & 0.8 \\
\cline { 2 - 5 } & $\%$ & $5 \%$ & $3 \%$ & $6 \%$ \\
\hline \multirow{2}{*}{ Renewables } & EJ & 1 & 2.1 & 1.7 \\
\cline { 2 - 5 } & $\%$ & $7 \%$ & $14 \%$ & $13 \%$ \\
\hline \multirow{2}{*}{ Total } & EJ & 13.4 & 14.8 & 12.5 \\
\hline
\end{tabular}

As in other demand sectors, between 2010 and 2050 the Reference scenario experiences slightly increasing energy consumption, with Policy Success producing a slight decrease (resulting from the selection of more energy-efficient technologies). Energy carrier profiles also remain largely similar, both over time and between scenarios. The only significant difference over time in both scenarios is the use of natural gas halving as a proportion of total consumption, and a doubling in the use of biomass (largely for use in the chemicals industry). Between scenarios, the only substantial difference in fuel mix by 2050 is the use of coal, which more than doubles in proportional terms in the Reference, but decreases substantially in Policy Success. Due to the changes in total energy consumption, such changes mean absolute demand for coal between the scenarios diverges even more.

However, this does not explain the significant differences in industrial emission developments between the scenarios - increasing by around 3\% in the Reference between 2010 and 2050, but decreasing by 61\% in Policy Success, respectively. Whilst the difference in the use of coal is a significant explanatory variable, the use of CCS in capturing industrial process emissions (in the iron and steel industry, in particular), from 2025 in Policy Success is much more important, sequestering around half of industry's $\mathrm{CO}_{2}$ emissions by 2050. 


\section{Energy System Costs and Shadow Marginal $\mathrm{CO}_{2}$ Price}

Figure 5 illustrates total energy system costs for the two scenarios. Pre-2020 values are not presented (as system costs are largely equivalent between the two scenarios in 2015 at around $\$ 2.6$ trillion).

Figure 5 - Total Energy System and Annualised Power Sector Investment Cost

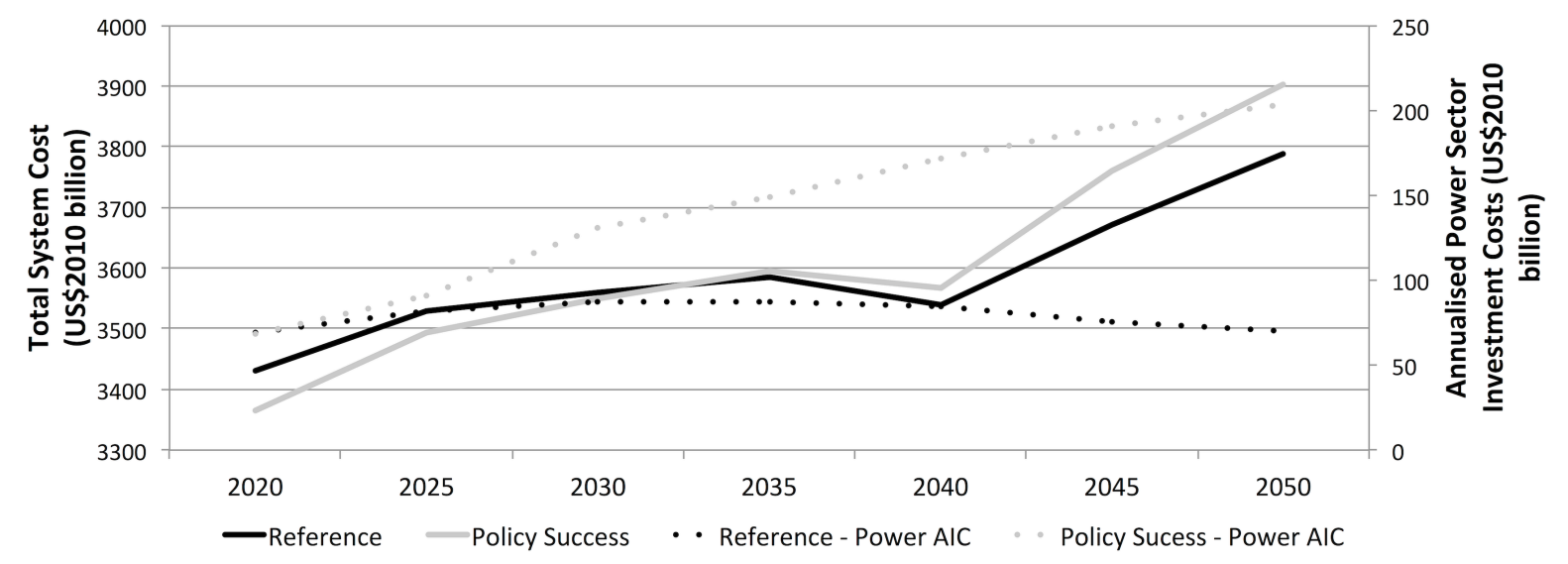

From 2020 onwards it is clear that there is still relatively little difference between the scenarios in terms of total system cost. A significant factor is differing fuel costs between the scenarios (Table ). The net present values (NPV) of total energy system cost across the assessment horizon, the objective function the model seeks to minimise, are \$29.17 trillion for the Reference and \$33.2 trillion for Policy Success. As such, it appears that the investment in the European energy system required to reach an $80 \% \mathrm{CO}_{2}$ reduction by 2050 (from 1990 levels) is around $14 \%$ higher than if decarbonisation efforts in the EU were abandoned post2020.

Required investments in the power sector differ more between scenarios than overall system costs. Reference scenario annualised investment costs peak in around 2030 at approximately $\$ 88 \mathrm{bn}$, whilst Policy Success costs steadily increase to a peak in 2050 at around $\$ 203 \mathrm{bn}$. The profiles of investment are as expected, with coal the focus in the Reference scenario, and wind, solar and nuclear, with higher capital costs, comprising the bulk of investment in Policy Success.

In working to meet a given $\mathrm{CO}_{2}$ emission constraint, the model produces a marginal abatement cost of $\mathrm{CO}_{2}$ (a shadow carbon price). The Reference scenario price peaks in 2020 at around $\$ 120 / \mathrm{tCO}_{2}$ before decreasing to zero, reflecting the lack of continued emission constraints. For Policy Success, prices increase steadily to $\$ 300 / \mathrm{tCO}_{2}$ in 2050 . These are 
weighted average EU values. The specific $\mathrm{CO}_{2}$ constraints placed on the UK \& Ireland and Germany produce higher marginal prices in these regions - up to $\$ 470 / \mathrm{tCO}_{2}$ for Germany and $\$ 300 / \mathrm{tCO}_{2}$ for the UK \& Ireland in 2050 . The influence of these regions raises the value of $\$ 280 / \mathrm{tCO}_{2}$ experienced in all other regions to reach the weighted average of $\$ 300 / \mathrm{tCO}_{2}$.

\section{Discussion}

Table 12 presents the evolution of $\mathrm{CO}_{2}$ emission reductions from 1990 in Policy Success, and the range of results for the 'decarbonisation' scenarios in the Commission's Energy Roadmap 2050 (ER2050), which analyse an 85\% reduction in $\mathrm{CO}_{2}$ from the energy system in the EU27 (European Commission, 2011a and European Commission, 2011b). Table 13 compares other key variables for Policy Success and the 'Diversified Supply Technologies' (DST) scenario in ER2050 (in which all energy sources compete on an open market with no specific support measures, and which is therefore comparable to Policy Success).

Table 12 - $\mathrm{CO}_{2}$ Emissions - Comparison with EU 2050 Energy Roadmap

\begin{tabular}{|c|c|c|c|c|c|c|}
\hline \multirow[t]{2}{*}{ Sector } & \multicolumn{3}{|c|}{$\begin{array}{l}\text { EU } 2050 \text { Energy Roadmap (All Decarbonisation } \\
\text { Scenarios) - change from } 1990 \mathrm{CO}_{2} \text { Emissions }\end{array}$} & \multicolumn{3}{|c|}{$\begin{array}{l}\text { ETM-UCL Results - Change } \\
\text { from } 1990 \mathrm{CO}_{2} \text { Emissions }\end{array}$} \\
\hline & 2020 & 2030 & 2050 & 2020 & 2030 & 2050 \\
\hline Power & $-33 \%$ to $-37 \%$ & $-48 \%$ to $-65 \%$ & $-96 \%$ to $-99 \%$ & $-34 \%$ & $-62 \%$ & $-152 \%$ \\
\hline Transport $^{12}$ & $+22 \%$ & $+5 \%$ to $+9 \%$ & $-60 \%$ to $-62 \%$ & $+17 \%$ & $+18 \%$ & $-10 \%$ \\
\hline Buildings (Res. \& Com.) & $-28 \%$ to $-40 \%$ & $-40 \%$ to $-46 \%$ & $-86 \%$ to $-88 \%$ & $-55 \%$ & $-31 \%$ & $-36 \%$ \\
\hline Industry & $-43 \%$ to $-44 \%$ & $-45 \%$ to $-48 \%$ & $-77 \%$ to $-79 \%$ & $-51 \%$ & $-64 \%$ & $-65 \%$ \\
\hline
\end{tabular}

Table 13 - Other Results - Comparison with EU 2050 Energy Roadmap

\begin{tabular}{|c|c|c|c|}
\hline \multirow{3}{*}{ Power Generation Profile (2050) } & Fossil Fuel & $20 \%$ & $25 \%$ \\
\cline { 2 - 4 } & Nuclear & $24 \%$ & $16 \%$ \\
\cline { 2 - 4 } & Renewables & $56 \%$ & $59 \%$ \\
\hline \multirow{2}{*}{ Marginal Abatement Cost in 2050 $\left(€ / \mathrm{tCO}_{2}\right)$} & $\$ 300(\sim 220)$ & $€ 265$ \\
\hline
\end{tabular}

Sectoral developments are relatively similar to 2030 between Policy Success and the ER2050 scenarios, but with significant divergence occurring thereafter. The ER2050 scenarios project almost full decarbonisation of the power sector by 2050, with remaining sectors reducing $\mathrm{CO}_{2}$ between $60 \%$ and $88 \%$. The results of the present paper project a less even distribution of abatement efforts, with the power sector clearly bearing by far the largest burden. The electricity generation profiles of Policy Success and DST are similar, although total generation in 2050 is over $25 \%$ higher in DST than in Policy Success, to satisfy increased electrification of

\footnotetext{
${ }^{12}$ Excluding aviation and shipping.
} 
final demand sectors. However, the key difference is the use of BECCS in Policy Success. This technology is essential in meeting the targets imposed by the Policy Success scenario, and is similar to the results of previous modelling studies including Azar et al (2006), Van Vuuren et al, (2007) and Edenhofer et al (2010). However, many other studies do not consider BECCS to be vital, and often do not allow its use at all - including the ER2050 scenarios. Capros et al (2014) tested seven different decarbonisation scenarios for the EU with seven large-scale energy-economy models, and found technically feasible solutions across all scenarios and models in the absence of BECCS. Knopf et al (2013) produced similar results.

Whilst abatement in the industry sector is relatively similar between the two studies (and delivered via similar means), both the transport and buildings sectors shoulder a much reduced abatement burden in the Policy Success scenario compared with ER2050 scenarios. For the latter, in the transport sector, decarbonisation is largely achieved by electrification of cars and LGVs coupled with a modal shift in (mostly freight) transport from road to rail. In the buildings sector, decarbonisation is significantly driven through improved building envelope efficiency. As options for optimising transport modal split and building fabric efficiency (which may exhibit low or even negative marginal $\mathrm{CO}_{2}$ abatement costs) are not available in the ETM-UCL, along with demand elasticities, the remaining relatively high-cost abatement options for these sector mean the model instead optimises to produce further abatement in other sectors (mainly power generation). It is likely that if such options were available in the ETM-UCL the abatement burden between sectors would be less polarised, deployment of BECCS would be lower (and possibly removed), and the additional cost of decarbonisation (and marginal $\mathrm{CO}_{2}$ abatement costs), discussed below, would be reduced.

Total energy system cost in relation to GDP is difficult to compare between studies, as GDP is often calculated endogenously (and thus varies between scenarios), using different growth rate assumptions, or annualised costs rather than cumulative or NPV values are presented. The ER2050 study, which similarly assumes no difference in GDP growth between scenarios, calculates a net benefit associated with decarbonisation, achieved through a significant reduction in fossil fuel requirements and associated costs. This is at odds with much of the literature, which suggests decarbonisation presents a positive, albeit a relatively small additional cost of between $0.2 \%$ and 1\% of average annual GDP between 2015 and 2050 (Capros et al, 2014). 
A long-term marginal abatement cost reaching $\$ 300 / \mathrm{tCO}_{2}$ (approximately $€ 220 / \mathrm{tCO}_{2}$ ) in 2050 is towards the low end of the results projected by other studies, including the ER2050 DST scenario. The median value produced by Knopf et al (2013) is $€ 521 / \mathrm{tCO}_{2}$ by 2050 , whilst values produced by the various models in Capros et al (2014) range between $€ 243 / \mathrm{tCO}_{2}$ and $€ 565 / \mathrm{tCO}_{2}$. Other studies by Capros et al (2012) and Hubler \& Loschel (2013) produce values of $€ 190 / \mathrm{tCO}_{2}$ and $€ 164 / \mathrm{tCO}_{2}$, respectively. However, the inclusion in the model of demand response to increased energy prices, and of building energy efficiency improvements, would be likely to reduce the energy system costs and marginal carbon prices in the Policy Success scenario, perhaps substantially.

Of course, key elements of model and scenario design, other than those described above, also factor into the differences presented. This includes assumptions regarding GDP growth and fossil fuel prices. The ER2050 scenarios assume annual GDP growth of $1.7 \%$ from 2005, whilst this analysis assumes initial growth rates of $2 \%$ from 2010 , reducing to $1.7 \%$ (Table ). In the Reference scenarios in both studies, all fossil fuel import prices increase from (similar) 2010 levels in line with global demand. However in ER2050 the oil price reaches a lower peak, whilst coal and natural gas prices attain higher values than those in Table. In the ER2050 decarbonisation scenarios oil prices decrease from 2010 levels, whilst the values used in Policy Success project an increase of nearly 12\% above the 2010 level by 2050, although prices stabilise over 2020-2035 and decline somewhat thereafter. Coal prices decrease by around 10\% in ER2050 and a third in Policy Success. Natural gas prices in both scenarios peak at around 2030 then fall back to 2010 levels by 2050. Other differences between the modelling exercises include projected technology costs, their availability, efficiencies and build rates for different sectors, and assumed renewable resource potentials, along with the base year, geographical scope and definition, and objective function of the models.

\section{Conclusions}

The objective of this paper is to examine the implications for the EU's energy system if an $80 \%$ reduction in $\mathrm{CO}_{2}$ emissions is to be achieved by 2050 against 1990 levels. This was carried out by using the recently developed European TIMES Model (ETM-UCL) to project a least-cost pathway (in Net Present Value terms) for achieving this aim ('Policy Success'). A Reference scenario (no $\mathrm{CO}_{2}$ constraints post-2020) was analysed to allow for comparison. The key conclusions are the following: 
- In the absence of transport mode-switching and building fabric energy efficiency improvements, the achievement of negative emissions in the power sector via the use of BECCS is essential in producing a technically feasible decarbonisation pathway. CCS is also required for extensive decarbonisation of the industrial sector. This highlights the need for an effective multi-sectoral strategy and appropriate policy frameworks to achieve it, to avoid such dependence.

- The additional cost of the Policy Success scenario is projected at approximately $\$ 4.33$ trillion (NPV), 14\% higher than the Reference scenario system cost. The macroeconomic implications of this extra investment are unclear. In itself it could provide an economic stimulus, increasing GDP, but this would be offset wholly or partially by the economic impact of the higher energy prices implied by the higher energy system cost.

- Average EU-wide marginal $\mathrm{CO}_{2}$ abatement costs in Policy Success reach $\$ 300 / \mathrm{tCO}_{2}$ in 2050 (with $\$ 470 / \mathrm{tCO}_{2}$ for Germany, $\$ 300 / \mathrm{tCO}_{2}$ for the UK \& Ireland, and $\$ 280 / \mathrm{tCO}_{2}$ in all other regions). Such a value is within the (wide) range of marginal carbon prices produced by comparable scenarios in other studies. However, it would be reduced, perhaps substantially, by the inclusion in the model of demand response to energy price increases or building energy efficiency improvement options.

\section{References}

Azar, C., Lindgren, K., Larson, E., Mollersten, K. (2006) Carbon Capture and Storage from Fossil Fuel and Biomass - Costs and Potential Role in Stabilising the Atmosphere, Climatic Change, 74, 47-79

Bruninx, K., Madzharov, D., Delarue, E., D’haeseleer, W. (2013) Impact of a German Nuclear Phase-Out on Europe's Electricity Generation - A Comprehensive Study, Energy Policy, 60, 251-261

Buchan, D. (2012) The Energiewende - Germany's Gamble, Available at: http://www.oxfordenergy.org/wpcms/wp-content/uploads/2012/06/SP-261.pdf [Accessed 17th March 2014]

Capros, P., Paroussos, L., Fragkos, P., Tsani, S., Boitier, B., Wagner, F., Busch, S., Resch, G., Blesl, M., Bollen, J. (2014) European Decarbonisation Pathways under Alternative Technological and Policy Choices: A MultiModal Analysis, Energy Strategy Reviews, 2, 231-245

Capros, P., Tasios, N., De Vita, A., Mantzos, L., Paroussos, L. (2012) Model-Based Analysis of Decarbonising the EU Economy in the Time Horizon to 2050, Energy Strategy Reviews, 1, 76-84 
Den Elzen, M.G.J., van Vuuren, D.P., van Vilet, J.. (2010) Postponing emission reductions from 2020 to 2030 increases climate risks and long-term costs, Climatic Change, 99, 313-320

Edenhofer, O., Knopf, B., Barker, T., Baumstark, L., Bellevrat, E., Chateau, B., Criqui, P., Isaac, M., Kitous, A., Kypreos, S., Leimbach, M., Lessmann, K., Magne, B., Scrieciu, S., Turton, H., van Vuuren, D.P. (2010) The Economics and Low Stabilisation: Model Comparison of Mitigation Strategies and Costs, The Energy Journal, $31,223-241$

European Commission (2011a) Communication from the Commission to the European Parliament, The Council, the European Economic and Social Committee and the Committee of the Regions - Energy Roadmap 2050 (COM (2011) 885/2), Brussels, European Commission

European Commission (2011b) Impact Assessment Accompanying the Document: Communication from the Commission to the European Parliament, The Council, the European Economic and Social Committee and the Committee of the Regions - Energy Roadmap 2050 (SEC (2011) 1565), Brussels, European Commission

European Commission (2014a) 2013 Framework for Climate and Energy Policies, Available at: http://ec.europa.eu/clima/policies/2030/index_en.htm [Accessed: 28th January 2014]

European Commission (2014b) The EU Emissions Trading System (EU ETS), Available at: http://ec.europa.eu/clima/policies/ets/index_en.htm [Accessed 17th March 2014]

European Commission (2014c) Effort Sharing Decision, Available at: http://ec.europa.eu/clima/policies/effort/index_en.htm [Accessed 17th March 2014]

European Environment Agency (2006) How Much Bioenergy can Europe Produce without Harming the Environment?, European Environment Agency, Copenhagen

European Environment Agency (2014) EEA Greenhouse Gas Data Viewer, Available at: http://www.eea.europa.eu/data-and-maps/data/data-viewers/greenhouse-gases-viewer [Accessed: 17th March 2014]

EUROSTAT (2012) Energy Production and Imports, Available at: http://epp.eurostat.ec.europa.eu/statistics_explained/index.php/Energy_production_and_imports [Accessed 10th April 2014]

Hubler, M. and Loschel, A. (2013) The EU Decarbonisation Roadmap 2050 - What Way to Walk?, Energy Policy, $55,190-207$

IEA (2012) Energy Technology Perspectives 2012: Pathways to a Clean Energy System, IEA/OECD, Paris 
Knopf, B., Chen, Y-H.H., De Cian, E., Forster, H., Kanudia, A., Karkatsouli, I., Keppo, I., Koljonen, T., Schumacher, K., Van Vuuren, D. (2013) Beyond 2020 - Strategies and Costs for Transforming the European Energy System, Climate Change Economics, 4, 4-42

Solano, B. and Pye, S. (2014) European TIMES Model (ETM-UCL), Available at: www.ucl.ac.uk/energymodels/models/etm-ucl

Solano, B. and Drummond, P. (2014) Techno-Economic Scenarios for Reaching Europe's Long-Term Climate Targets: Using the European TIMES Model (ETM-UCL) to Model Energy System Development in the EU, University College London, London

Wesselink, B., Harmsen, R., Eichhammer, W. (2010) Energy Savings 2020: How to Triple the Impact of Energy Saving Policies in Europe, European Climate Foundation

World Nuclear Association (2013) World Nuclear Association - Country Profiles, Available at: http://www.worldnuclear.org/info/Country-Profiles/ [Accessed: $25^{\text {th }}$ October 2013]

Van Vuuren, D.P., den Elzen, M.G.J., Lucas, P.L., Eickhout, B., Strengers, B., van Ruijven, B., Wonink, S., van Houdt, R. (2007) Stabilising Greenhouse Gas Concentrations at Low Levels: An Assessment of Reduction Strategies and Costs, Climatic Change, 81, 119-159 